Published in final edited form as:

Curr Treat Options Psychiatry. 2017 March ; 4(1): 33-46. doi:10.1007/s40501-017-0102-4.

\title{
Pharmacological Management of Anxiety Disorders in the Elderly
}

\author{
Elizabeth A. Crocco, M.D., Sindy Jaramillo, M.D., Caroline Cruz-Ortiz, M.D., and Katherine \\ Camfield, B.S. \\ Center on Aging, Department of Psychiatry and Behavioral Sciences, University of Miami, Miller \\ School of Medicine, Miami, Florida, USA
}

\section{Opinion Statement}

Anxiety disorders are common in the elderly. Additionally, anxiety symptoms often accompany co-morbid psychiatric, medical, as well as neurodegenerative diseases in the older population. Anxiety in the elderly, often accompanied by depression, can lead to worsening physical, cognitive and functional impairments in this vulnerable population. Antidepressants are considered first line treatment. Both SSRIs and SNRIs are efficacious and well-tolerated in the elderly. Some SSRIs are strong inhibitors of the cytochrome $\mathrm{P} 450$ hepatic pathway whereas others have less potential for drug interaction. Those antidepressants with more favorable pharmacokinetic profiles should be considered first-line in the treatment of anxiety. Mirtazapine and vortioxetine are also considered safe treatment options. Buspirone may have benefit, but lacks studies in elderly populations. Although tricyclic/tetracyclic antidepressants (TCAs) and monoamine oxidase inhibitors (MAOIs) may be effective in the elderly, their side effect and safety profiles are suboptimal and thus are not recommended in late-life. Benzodiazepines and beta blockers should generally be avoided when treating anxiety in the elderly. There is not enough evidence to support the use of antipsychotics or mood stabilizers given their risk of problems in both the long and short term. In addition, antipsychotics have a black box warning for increased mortality in elderly patients with dementia.

\section{Keywords}

Anxiety; Anxiety disorders; Elderly; Older adults; Selective serotonin reuptake inhibitors; Serotonin and norepinephrine reuptake inhibitors

Correspondence to: Dr. Crocco, Department of Psychiatry and Behavioral Sciences Miller School of Medicine/University of Miami, 1695 NW $9^{\text {th }}$ Avenue, Suite 3204A (D101) Miami, FL 33136, Tel \# 305-355-9065, Fax \# 305-355-7086, ecrocco@ med.miami.edu.

Compliance with Ethics Guidelines

Conflict of Interest

Katherine Camfield, Caroline Cruz-Ortiz, Sindy Jaramillo declare that they have no conflict of interest.

Elizabeth Crocco reports grants from Otsuka Pharmaceutical Development \& Commercialization, Inc, grants from Avanir

Pharmaceuticals, personal fees from Mantovani Foundation, Milan, Italy, personal fees from Primed, personal fees from Baptist

Health, outside the submitted work.

Human and Animal Rights and Informed Consent

This article does not contain any studies with human or animal subjects performed by any of the authors. 


\section{Introduction}

According to the Population Reference Bureau, the number of Americans ages 65 and older is projected to more than double from 46 million today to over 98 million by 2060 . Additionally, the 65-and-older age group's share of the total population will rise to nearly 24 percent from 15 percent. [1] Anxiety disorders are among the most prevalent mental health issues in the elderly [2]. A systematic literature review revealed that the prevalence of anxiety disorders in clinical settings ranges from $1.2 \%$ to $28 \%$ in elderly patients [3]. Additionally, a population-based study found that $18 \%$ of elderly patients receiving contracted home care in the United States have some type of anxiety disorder [4]. The most common anxiety disorders seen in older adults include generalized anxiety disorder and simple phobia $[3,5,6]$. It is important to note, however, that anxiety symptoms in the elderly that do not meet full DSM-V criteria can still lead to significant impairment and disability, requiring intervention.

Anxiety disorders in the elderly appear to be more likely associated with common medical conditions than those found in the general population [7]. Comorbid anxiety can complicate a patient's medical treatment and outcome. For example, the incidence of anxiety disorders in chronic obstructive pulmonary disease (COPD) patients is exceedingly common and ranges between $13 \%$ to $46 \%$. Anxiety in these individuals is associated with functional limitations, poorer exercise tolerance, suicidal ideation and higher frequency of hospitalizations $[8,9]$. Anxiety and depression are also highly prevalent in patients with diabetes. A cross-sectional study of anxiety and depression in type 2 diabetes patients estimated prevalence to be $56.1 \%$ and $43.6 \%$, respectively. The combination of depressive symptoms and anxiety symptoms in these patients was associated with poor glycemic control [10].

It is well-established that depression with co-occurring anxiety has been associated with an increased risk of cardiovascular and cerebrovascular morbidity and mortality [11,12]. A recent systematic review concluded that the incidence rate for anxiety disorders after cardiac arrest varies from $13 \%$ to $42 \%$ [13]. Anxiety symptoms also frequently accompany patients with neurodegenerative diseases such as Alzheimer's and Parkinson's disease [14,15]. Elderly patients with cognitive disorders often have faster cognitive and functional loss when accompanied by behavioral problems that may present with anxiety symptoms. Anxiety symptoms should be assessed in the context of medical or cognitive impairments in order to provide the right treatment and improve older individuals' over all well-being and outcome.

The pharmacological treatment of anxiety disorders in the elderly is complex at several levels. Multiple medical co-morbidities can lead to worsening of psychiatric symptoms, and the use of psychiatric medications can potentially cause side effects, intolerability and drugdrug interactions. Pharmacologic evidence for the treatment of anxiety in the elderly is limited. As such, clinicians must formulate an individualized approach to treatment, combining available guidelines from geriatric medicine and anxiety treatment for a youngeradult population. This paper reviews available evidence of pharmacological approaches to treatment of anxiety in the elderly. 


\section{Antidepressants}

Antidepressants are the first-line treatment in anxiety disorders [16]. The selective serotonin reuptake inhibitors (SSRIs) and serotonin norepinephrine reuptake inhibitors (SNRIs) are more commonly used in the elderly, due to their tolerability and safety profile in this population [17]. Although tricyclic/tetracyclic (TCA) antidepressants and monoamine oxidase inhibitors (MAOIs) are indicated for select anxiety disorders, they are not considered first-line treatment of anxiety disorders in elderly patients due to side effects and safety considerations.

\section{Serotonin Specific Reuptake Inhibitors (SSRIs)}

Escitalopram is FDA-approved for the treatment of generalized anxiety disorder (GAD) and has demonstrated improvement in anxiety symptoms when compared with placebo in older adults $[18,19]$. Additionally, escitalopram prevents symptom relapse. When augmented with cognitive behavioral therapy (CBT), it decreases the need for long-term pharmacotherapy use [20]. In a recent study that included elderly subjects with social anxiety, the efficacy and tolerability of escitalopram versus placebo was compared. The primary efficacy analysis showed no difference for escitalopram $10 \mathrm{mg}$ versus placebo. However, there was a statistically significant difference when escitalopram $20 \mathrm{mg}$ was compared to placebo. The most common side effects were somnolence, nausea and ejaculation disorders similar to younger subjects [21]. Escitalopram and citalopram also demonstrated benefit for treatment of elderly individuals with panic disorder [22].

Citalopram has demonstrated statistically significant improvement in anxiety among elderly patients when compared with placebo [23]. In a randomized, double blind, placebo-control study, the effects of citalopram on psychiatric and behavioral symptoms in Alzheimer's disease was evaluated. The study concluded that there was a significant decrease in anxiety symptoms after 9 weeks of citalopram use when compared with placebo [24]. An open-label trial examined the impact of citalopram on anxiety symptoms, when Parkinson's disease patients are treated for depression. The study showed that $50 \%$ of the patients whose depression responded had a statistically significant decrease in anxiety symptoms. The same study reported that $70 \%$ of the patients reported only mild adverse events, with no serious adverse events [25]. Special consideration has to be taken when citalopram is prescribed for elderly patients with cardiovascular problems. Due to the propensity to cause abnormal cardiac conductivity, the dose of citalopram should not be higher than $40 \mathrm{mg} /$ day in those under 65 years of age, and no higher than $20 \mathrm{mg} /$ day in individuals over 65 [26,27].

Sertraline is FDA-approved for the treatment of panic disorder and social anxiety disorder and has demonstrated effectiveness over worry symptoms when compared with CBT in the elderly [28]. In a randomized single-blinded trial, sertraline was compared with buspirone in the treatment of GAD in the elderly. Both medications appear to be well tolerated and have good efficacy. There was no report of any serious adverse events during an 8-week period [29]. Sertraline may also improve anxiety symptoms andexecutive function in stage III or IV cancer patients [30]. 
Paroxetine is an FDA-approved SSRI for use in generalized anxiety disorder and panic disorder; however, it has been associated with more weight gain [31]. Paroxetine is the SSRI with the most anticholinergic side effects which may lead to dry mouth, constipation, blurry vision, urinary retention as well as confusion in older individuals [32]. Additionally, paroxetine is a potent inhibitor of the cytochrome P450 2D6 hepatic pathway and therefore has considerable potential for drug interactions with patients taking other medications [33]. Fluoxetine, which is also FDA-approved for panic disorder as well as social anxiety disorder, and fluvoxamine are also both significant inhibitors of select $\mathrm{P} 450$ hepatic pathways $[34,35]$. For these reasons, these SSRIs may not be optimal in late-life anxiety.

Common side effects from SSRI use in both general adults and the elderly may include gastrointestinal distress, insomnia, sexual side effects, somnolence, and headaches. In the elderly, upper gastrointestinal tract bleeding was nine times more common over three months in patients on an SSRI and a nonsteroidal anti-inflammatory medication than in a control group not on those medications. Additionally, a two-fold increase in bone mineral density loss and hip fractures with use of SSRIs has been documented [36,37]. Hyponatremia due to the syndrome of inappropriate antidiuretic hormone secretion (SIADH) is more frequently seen in elderly SSRI users. Table 1 shows the SSRIs recommended for use in anxiety in the elderly.

\section{Serotonin and Norepinephrine Reuptake Inhibitors (SNRIs)}

Venlafaxine is FDA-approved for GAD and social anxiety disorder and has been found effective for treatment of anxiety in the elderly [38] Similar to the side effect profile in SSRIs, sexual side effects are seen with venlafaxine, as well as sweating. In a randomized placebo-controlled trial study of adult subjects with generalized anxiety disorder, escitalopram was compared with venlafaxine. The two drugs showed equal efficacy, but there was a significantly increased rate of discontinuation due to secondary side effects for venlafaxine [39]. Venlafaxine also showed statistically significant increase in systolic and diastolic blood pressure, after 8 weeks of treatment [39]. These findings may indicate that SSRIs such as escitalopram may be a better tolerated first line treatment over SNRIs in the elderly patient with cardiovascular disease.

Duloxetine is FDA-approved for GAD and had and has similar efficacy and side effect profile to SSRIs [40]. Additionally, blood pressure effects were not as significant as with venlafaxine [41]. Side effects include liver abnormalities. Although this risk is low, duloxetine should not be considered in patients with hepatic impairment. Excessive sweating as well as urinary retention, although infrequent, is a concern in the elderly [42]. Table 2 lists SNRIs and other antidepressants recommended for use in anxiety in the elderly.

\section{Tricyclic/Tetracyclic Antidepressants (TCAs)}

Tricyclic and tetracyclic antidepressants (TCAs) are effective in the treatment of anxiety disorders, such as panic disorder, GAD and social anxiety disorder. TCAs commonly prescribed include imipramine, amitriptyline, nortriptyline, and desipramine. There are no specific studies of use of TCAs in the elderly for anxiety. Extrapolation from adult studies 
suggests that TCAs may be helpful in the elderly [43]. TCAs, such as amitriptyline, also play a role in the treatment of neuropathic pain and headaches. Side effect profiles including anticholinergic, adrenergic, as well as cardiac conduction effects significantly limit use in older adults. Anticholinergic side effects may include orthostatic hypotension, falls, urinary retention as well as confusion. Because of significant side effect and safety considerations, TCAs are not recommended as a primary treatment option of anxiety in elderly patients.

\section{Monoamine Oxidase Inhibitors (MAOIs)}

MAOIs such as tranylcypromine and phenelzine have long been efficacious in treatmentresistant depression [44]. In adult studies, they have also been found to be efficacious in panic and social anxiety disorder [45]. Caution should be used when extrapolating these results for the elderly given risk of orthostatic hypotension, falls and hypertensive crisis. MAOIs are not recommended in the elderly for the primary treatment of anxiety.

\section{Mirtazapine}

No published studies have focused exclusively on late-life anxiety disorders and mirtazapine. However, one study [46] focused on mirtazapine use in PTSD in older individuals with a mean age of 59. In this study, mirtazapine was found to be efficacious for PTSD in this age group. Mirtazapine is recommended in the elderly given its safe side effect profile and minimal drug-drug interaction. In addition, side effects can be used to our advantage as mirtazapine can help with insomnia and increase appetite in patient with weight loss. Patients with anxiety and difficulty with sleep or appetite can benefit tremendously from mirtazapine and it can be considered as a safe treatment option.

\section{Vortioxetine}

Vortioxetine is a new antidepressant with anxiolytic effects [47]. It is a serotonin modulator and stimulator that not only enhance serotonin activity but also increases the levels of norepinephrine and dopamine in ventral and medial prefrontal cortexes in rat models [48]. Vortioxetine is well- tolerated in elderly patients. When compared with placebo and duloxetine, nausea was the most common side effect in vortioxetine [49]. Vortioxetine also showed significant improvement in cognition in patients with Major Depressive Disorder associated with previous cognitive decline [49,50]. Additionally, vortioxetine appears to enhance contextual and episodic memory and reverse memory deficits in the animal models [50,51]. Given its favorable side effect profile, improvements in cognition as well as favorable outcome in clinical trials focused on elderly depressed subjects, vortioxetine can be a useful treatment option of anxiety in the elderly.

\section{Buspirone}

There are no randomized controlled trials evaluating buspirone for treatment of anxiety in the elderly. However, extrapolation from adult studies indicates that this could be a potential valuable adjunct for anxiety disorders [52, 53]. Buspirone has been found to be efficacious in GAD with less side effects than benzodiazepines. In fact, there are several case reports indicating it can be helpful in agitation and anxiety in patients with dementia [54, 55]. 
Buspirone does not cause respiratory depression, cognitive impairment or falls. However, it may have higher discontinuation rates, perhaps due to longer lag time to effectiveness.

\section{Benzodiazepines}

Benzodiazepines are commonly used in adults with anxiety disorders as adjunctive treatment when a patient is started on an antidepressant, such as an SSRI or SNRI. The goal is usually for efficacy in the short-term while the antidepressant is given time to take effect. In the elderly population, however, the risks often outweigh the benefits and they need to be used with caution. If absolutely needed, it is recommended that the physician prescribes lorazepam, oxazepam or temazepam as these do not have active metabolites because they are metabolized by conjugation only. Benzodiazepine use in the elderly can lead to falls [56], hip fractures [57], and cognitive impairment [58, 59]. More recent studies have even found possible links between benzodiazepine use and dementia [60].

\section{Antipsychotics}

First generation antipsychotics are generally avoided in the elderly due to significant side effects and safety issues. However, atypical antipsychotics are frequently prescribed offlabel in the elderly to treat behavioral and psychiatric symptoms, especially in nursing homes [61]. It should be noted that there is a black box warning for both typical and atypical antipsychotics in the elderly with dementia due to increased mortality rates [62]. Although atypical antipsychotics are not FDA-approved for the treatment of anxiety disorders in the general population, there is some evidence to support their off-label use in select situations.

Out of all the atypical antipsychotic medications, quetiapine has shown efficacy in the treatment of GAD [63]. Pooling several clinical trials, it was found that quetiapine was better than placebo in both the maintenance and treatment of GAD [64]. Although not as strong as for monotherapy, there are also some studies that support quetiapine as an adjunctive therapy [65]. Special consideration must be paid to dosing when using quetiapine adjunctively. Co-administration with fluvoxamine will increase serum quetiapine levels [66]. It should be noted that although the use of quetiapine may be effective, there is not enough safety data for its use as GAD monotherapy, and longer term studies still need to be done to be approved as an indication by the FDA.

Evidence for use of atypical antipsychotics to treat other anxiety-related disorders is less robust. In particular, an Agency for Health Care, Research and Quality (AHRQ) review found that they may be beneficial in both obsessive-compulsive disorder (OCD) and posttraumatic stress disorder (PTSD). It found that studies of both risperidone and quetiapine have shown significant effects when used as augmentation to treatment with SSRIs [64]. In head to head studies of augmentation treatment, there was no significant difference between olanzapine and risperidone with an SSRI, while quetiapine has been shown to have better efficacy than ziprasidone as an adjuvant [64]. The same AHRQ review on antipsychotic medications for treating PTSD found evidence supporting risperidone, olanzapine, quetiapine as significantly superior to placebo [64]. 
Despite these results, the use, tolerability and safety profile of antipsychotics has not been well-studied in elderly patients with anxiety. Furthermore, their use warrants particular concern as many atypical antipsychotics may be associated with changes in metabolic function, and treatments that do not potentially alter endocrine status are preferred. Risk of death associated with the use of antipsychotic medication in cognitively impaired elderly also should preclude their use. In the long term, antipsychotics may also increase osteopenia and bone loss which can be profoundly detrimental in the elderly. They should not be considered a typical treatment regimen of anxiety in the elderly.

\section{Mood Stabilizers}

There is minimal evidence for the use of mood stabilizers in anxiety disorders, especially in the elderly. In addition, most studies of mood stabilizers in the elderly involve bipolar disorder as opposed to anxiety disorders and there are many limitations due to small sample size. Even lithium, which is one of the most well-known mood stabilizers, has minimal and mixed results that are not directly related to anxiety $[67,68,69]$

Anticonvulsant medications are another genre of drugs commonly used as mood stabilizers. There are several studies that support carbamazepine and lamotrigine in the treatment of post-traumatic stress disorder (PTSD), but results have been mixed with the use of valproate for PTSD [70]. Valproate has also shown some effectiveness in both panic disorder and social anxiety [70]. Lamotrigine has demonstrated studies that support its use in PTSD, panic disorder with agoraphobia, and unipolar depression with comorbid anxiety $[70,71,72]$. Despite these finding in adult patients, anticonvulsants have significant side effects, drug interactions and safety issues that can potentially affect older individuals. Cognitive slowing, tremor, liver abnormalities, rash, and sedation, can be disabling to elderly individuals. In general, these medications should not be used first-line in geriatric patients with anxiety disorders given side effect profiles.

\section{Beta-Blockers}

Beta-blockers are not commonly used in psychiatric treatment and are associated with development of psychiatric symptoms such as depression, sedation, and fatigue [73]. While there is evidence to support the use of beta-blockers to treat performance anxiety, their use is inot indicated to treat other forms of anxiety [74]. Several case studies have shown metoprolol may induce anxiety in elderly patients, which improves or resolves with discontinuation of the drug [75]. One thought is that beta-blockers such as metoprolol and propranolol are lipophilic and can thus cross the blood brain barrier [75,76]. These lipophilic drugs are also metabolized by the liver, which is an important consideration in elderly patients with comorbid heart or liver conditions as it can increase their circulating levels [76]. In addition, there are several other psychotropic medications that can affect betablocker efficacy and side effects. SSRIs, for example, can increase plasma concentrations of beta blockers; meanwhile, TCAs can exacerbate their hypotensive effects [77]. Betablockers are therefore not recommended for use in late-life anxiety disorders. 


\section{Conclusion}

In conclusion, there are very few studies examining pharmacological management of anxiety in the elderly Anxiety disorders will become prevalent in older adults and those with medical and neurodegenerative illnesses as this population continues to grow. Given the differences in pharmacokinetics, metabolism and vulnerability to medication side effects in the elderly, more randomized controlled trials will be needed to better understand the best anxiety treatment options for this group of Americans.

\section{References}

Recently published papers of particular interest have been highlighted as:

- Of importance

- Of major importance

1. [Accessed 3 Nov 2016] Population Bulletin. Dec. 2015 http://www.prb.org/pdf16/aging-uspopulation-bulletin.pdf

2. Andreas S, Schulz H, Volkert J, et al. Prevalence of mental disorders in elderly people: the European MentDis_ICF65 study. The British Journal of Psychiatry. 2016; doi: 10.1192/bjp.bp.115.180463

3. Bryant C, Jackson H, Ames D. The prevalence of anxiety in older adults: Methodological issues and a review of the literature. Journal of Affective Disorders. 2008; 109:233-250. [PubMed: 18155775]

4. Wang J, Kearney JA, Jia H, Shang J. Mental Health Disorders in Elderly People Receiving Home Care. Nursing Research. 2016; 65:107-116. [PubMed: 26938359]

5. Watterson RA, Williams JVA, Lavorato DH, Patten SB. Descriptive Epidemiology of Generalized Anxiety Disorder in Canada. The Canadian Journal of Psychiatry. 2016; doi: 10.1177/0706743716645304

6. Koychev I, Ebmeier K. Anxiety in older adults often goes undiagnosed. The practitioner. 2016; 260:17-20.

7. Fung AWT, Lam LCW. A cross-sectional study on clinical correlates of anxiety disorders in 613 community living older adults in Hong Kong. Int J Geriatr Psychiatry International Journal of Geriatric Psychiatry. 2016; doi: 10.1002/gps.4516

8. Yohannes AM, Alexopoulos GS. Depression and anxiety in patients with COPD. European Respiratory Review. 2014; 23:345-349. [PubMed: 25176970]

9. Willgoss TG, Yohannes AM. Anxiety Disorders in Patients With Chronic Obstructive Pulmonary Disease: A Systematic Review. Respiratory Care. 2012; doi: 10.4187/respcare.01862

10. Sun N, Lou P, Shang Y, Zhang P, Wang J, Chang G, Shi C. Prevalence and determinants of depressive and anxiety symptoms in adults with type 2 diabetes in China: a cross-sectional study. BMJ Open. 2016; doi: 10.1136/bmjopen-2016-012540

11. Cumming TB, Blomstrand C, Skoog I, Linden T. The High Prevalence of Anxiety Disorders After Stroke. The American Journal of Geriatric Psychiatry. 2016; 24:154-160. [PubMed: 26601725]

12. Moscati A, Flint J, Kendler KS. Classification Of Anxiety Disorders Comorbid With Major Depression: Common Or Distinct Influences On Risk? Depression and Anxiety Depress Anxiety. 2015; 33:120-127. [PubMed: 26418316]

13. Tully PJ, Harrison NJ, Cheung P, Cosh S. Anxiety and Cardiovascular Disease Risk: a Review. Current Cardiology Reports. 2016; doi: 10.1007/s11886-016-0800-3

14. Starkstein SE, Jorge R, Petracca G, Robinson RG. The Construct of Generalized Anxiety Disorder in Alzheimer Disease. The American Journal of Geriatric Psychiatry. 2007; 15:42-49. [PubMed: 17194814]

15. Martens KAE, Szeto JYY, Muller AJ, Hall JM, Gilat M, Walton CC, Lewis SJG. Cognitive Function in Parkinson's Disease Patients with and withoutAnxiety. Neurology Research International. 2016; 2016:1-7. 
16. Craske MG, Stein MB. Anxiety. The Lancet. 2016; 388:3048-3059.

17. Gonçalves DC, Byrne GJ. Interventions for generalized anxiety disorder in older adults: Systematic review and meta-analysis. Journal of Anxiety Disorders. 2012; 26:1-11. [PubMed: 21907538]

18. Lenze EJ. Escitalopram Treatment of Generalized Anxiety Disorder in Older Adults—Reply. Jama. 2009; 301:1987. [PubMed: 19454633]

19. Mohamed S, Osatuke K, Aslam M, Kasckow J. Escitalopram for comorbid depression and anxiety in elderly patients: A 12-week, open-label, flexible-dose, pilot trial. The American Journal of Geriatric Pharmacotherapy. 2006; 4:201-209. [PubMed: 17062320]

20**. Wetherell JL, Petkus AJ, White KS, Nguyen H, Kornblith S, Andreescu C, Zisook S, Lenze EJ. Antidepressant Medication Augmented With Cognitive-Behavioral Therapy for Generalized Anxiety Disorder in Older Adults. American Journal of Psychiatry. 2013; 170:782-789. This article showed positive outcome in using combination treatment of SSRI with CBT in older adults with anxiety. [PubMed: 23680817]

21. Asakura S, Hayano T, Hagino A, Koyama T. A randomized, double-blind, placebo-controlled study of escitalopram in patients with social anxiety disorder in Japan. Current Medical Research and Opinion. 2016; 32:749-757. [PubMed: 26808688]

22. Rampello L, Alvano A, Raffaele R, Malaguarnera M, Vecchio I. New Possibilities of Treatment for Panic Attacks in Elderly Patients. Journal of Clinical Psychopharmacology. 2006; 26:67-70. [PubMed: 16415709]

23. Lenze EJ, Mulsant BH, Shear MK, Dew MA, Miller MD, Pollock BG, Houck P, Tracey B, Reynolds CF. Efficacy and Tolerability of Citalopram in the Treatment of Late-Life Anxiety Disorders: Results From an 8-Week Randomized, Placebo-Controlled Trial. American Journal of Psychiatry. 2005; 162:146-150. [PubMed: 15625213]

24**. Leonpacher AK, Peters ME, Drye LT, et al. Effects of Citalopram on Neuropsychiatric Symptoms in Alzheimer's Dementia: Evidence From the CitAD Study. American Journal of Psychiatry AJP. 2016; 173:473-480. Demonstrated the use of citalopram improving neuropsychiatric symptoms including anxiety in Alzheimer's disease.

25. Menza M. Citalopram Treatment of Depression in Parkinson's Disease: The Impact on Anxiety, Disability, and Cognition. Journal of Neuropsychiatry. 2004; 16:315-319.

26. Bird ST, Crentsil V, Temple R, Pinheiro S, Demczar D, Stone M. Cardiac Safety Concerns Remain for Citalopram at Dosages Above 40 mg/Day. American Journal of Psychiatry. 2014; 171:17-19. [PubMed: 24399423]

27. Zivin K, Pfeiffer PN, Bohnert AS, Ganoczy D, Blow FC, Nallamothu BK, Kales HC. Safety of High-Dosage Citalopram. American Journal of Psychiatry. 2014; 171:20-22. [PubMed: 24399424]

28. Schuurmans J, Comijs H, Emmelkamp PM, Gundy CM, Weijnen I, Hout MVD, Dyck RV. A Randomized, Controlled Trial of the Effectiveness of Cognitive Behavioral Therapy and Sertraline versus a Waitlist Control Group for Anxiety Disorders in Older Adults. The American Journal of Geriatric Psychiatry. 2006; 14:255-263. [PubMed: 16505130]

29. Mokhber N, Azarpazhooh MR, Khajehdaluee M, Velayati A. Randomized, single-blind, trial of sertraline and buspirone for treatment of elderly patients with generalized anxiety disorder. Psychiatry and Clinical Neurosciences. 2010; 64:128-133. [PubMed: 20132529]

30. Li D-Q. Effects of Sertraline on Executive Function and Quality of Life in Patients with Advanced Cancer. Medical Science Monitor. 2014; 20:1267-1273. [PubMed: 25047152]

31. Fava M, Judge R, Hoog SL, Nilsson ME, Koke SC. Fluoxetine Versus Sertraline and Paroxetine in Major Depressive Disorder. The Journal of Clinical Psychiatry. 2000; 61:863-867. [PubMed: 11105740]

32. Kachru N, Carnahan RM, Johnson ML, Aparasu RR. Potentially inappropriate anticholinergic medication use in older adults with dementia. Journal of the American Pharmacists Association. 2015; 55:603-612. [PubMed: 26501745]

33. Wagstaff AJ, Cheer SM, Matheson AJ, Ormrod D, Goa KL. Paroxetine An Update of Its Use in Psychiatric Disorders in Adults. Adis Drugs evaluation. 2002; 62:655-703.

34. Abadie D, Rousseau V, Logerot S, Cottin J, Montastruc J-L, Montastruc F. Serotonin Syndrome. Journal of Clinical Psychopharmacology. 2015; 35:382-388. [PubMed: 26082973] 
35. Altamura AC, Caldiroli A, Buoli M. Pharmacokinetic evaluation of fluvoxamine for the treatment of anxiety disorders. Expert Opinion on Drug Metabolism \& Toxicology. 2015; 11:649-60. [PubMed: 25728382]

36*. Ak E, Bulut SD, Bulut S, Akdağ HA, Öter GB, Kaya H, Kaya OB, Şengül CB, Kısa C. Evaluation of the effect of selective serotonin reuptake inhibitors on bone mineral density: an observational cross-sectional study. Osteoporosis International. 2014; 26:273-279. Demonstrates the risk of bone density loss in patients using SSRI's. [PubMed: 25187118]

37. Richards JB. Effect of Selective Serotonin Reuptake Inhibitors on the Risk of Fracture. Archives of Internal Medicine. 2007; 167:188. [PubMed: 17242321]

38. Katz IR, Reynolds CF, Alexopoulos GS, Hackett D. Venlafaxine ER as a Treatment for Generalized Anxiety Disorder in Older Adults: Pooled Analysis of Five Randomized PlaceboControlled Clinical Trials. Journal of the American Geriatrics Society. 2002; 50:18-25. [PubMed: 12028242]

39. Bose A, Korotzer A, Gommoll C, Li D. Randomized placebo-controlled trial of escitalopram and venlafaxine XR in the treatment of generalized anxiety disorder. Depression and Anxiety. 2008; 25:854-861. [PubMed: 18050245]

40. Alaka KJ, Noble W, Montejo A, et al. Efficacy and safety of duloxetine in the treatment of older adult patients with generalized anxiety disorder: a randomized, double-blind, placebo-controlled trial. International Journal of Geriatric Psychiatry. 2014; 29:978-986. [PubMed: 24644106]

41. Delgado PL, Brannan SK, Mallinckrodt CH, Tran PV, Mcnamara RK, Wang F, Watkin JG, Detke MJ. Sexual Functioning Assessed in 4 Double-Blind Placebo- and Paroxetine-Controlled Trials of Duloxetine for Major Depressive Disorder. The Journal of Clinical Psychiatry. 2005; 66:686-692. [PubMed: 15960560]

42. Whiskey E, Taylor D. A review of the adverse effects and safety of noradrenergic antidepressants. Journal of Psychopharmacology. 2013; 27:732-739. [PubMed: 23784737] Mcleod DR, HoehnSaric R, Porges SW, Zimmerli WD. Effects of alprazolam and imipramine on parasympathetic cardiac control in patients with generalized anxiety disorder. Psychopharmacology. 1992; 107:535-540. [PubMed: 1603897]

43. Menkes D, Bosanac P, Castle D. MAOIs - does the evidence warrant their resurrection? Australasian Psychiatry. 2016; 24:371-373. [PubMed: 26917855]

44. Atiwannapat P, Arden PC, Stewart JW. Monoamine Oxidase Inhibitors for Various Psychiatric Disorders and Conditions. Psychiatric Annals. 2014; 44:567-573.

45. Chung MY, Min KH, Jun YJ, Kim SS, Kim WC, Jun EM. Efficacy and tolerability of mirtazapine and sertraline in Korean veterans with posttraumatic stress disorder: A randomized open label trial. Human Psychopharmacology: Clinical and Experimental. 2004; 19:489-494. [PubMed: 15378676]

46. Guilloux J-P, Mendez-David I, Pehrson A, et al. Antidepressant and anxiolytic potential of the multimodal antidepressant vortioxetine (Lu AA21004) assessed by behavioural and neurogenesis outcomes in mice. Neuropharmacology. 2013; 73:147-159. [PubMed: 23721744]

47. Pehrson AL, Cremers T, Bétry C, Hart MGVD, Jørgensen L, Madsen M, Haddjeri N, Ebert B, Sanchez C. Lu AA21004, a novel multimodal antidepressant, produces regionally selective increases of multiple neurotransmitters-A rat microdialysis and electrophysiology study. European Neuropsychopharmacology. 2013; 23:133-145. [PubMed: 22612991]

$48^{* *}$. Katona C, Hansen T, Olsen CK. A randomized, double-blind, placebo-controlled, duloxetinereferenced, fixed-dose study comparing the efficacy and safety of Lu AA21004 in elderly patients with major depressive disorder. International Clinical Psychopharmacology. 2012; 27:215-223. Improvement in depression and cognitive function in elderly depressed subjects. [PubMed: 22572889]

49. Jardin KGD, Jensen JB, Sanchez C, Pehrson AL. Vortioxetine dose-dependently reverses 5-HT depletion-induced deficits in spatial working and object recognition memory: A potential role for 5-HT1A receptor agonism and 5-HT3 receptor antagonism. European Neuropsychopharmacology. 2014; 24:160-171. [PubMed: 23916504]

50. Baldwin DS, Loft H, Dragheim M. A randomised, double-blind, placebo controlled, duloxetinereferenced, fixed-dose study of three dosages of Lu AA21004 in acute treatment of major 
depressive disorder (MDD). European Neuropsychopharmacology. 2012; 22:482-491. [PubMed: 22209361]

51. Chiaie RD, Pancheri P, Casacchia M, Stratta P, Kotzalidis GD, Zibellini M. Assessment of the Efficacy of Buspirone in Patients Affected by Generalized Anxiety Disorder, Shifting to Buspirone From Prior Treatment with Lorazepam. Journal of Clinical Psychopharmacology. 1995; 15:12-19. [PubMed: 7714222]

52. Howland RH. Buspirone: Back to the Future. J Psychosoc Nurs Ment Health Serv Journal of Psychosocial Nursing and Mental Health Services. 2015; 53:21-24.Colenda C. Buspirone In Treatment Of Agitated Demented Patient. The Lancet. 1988; 331:1169.

53. Cooper JP. Buspirone for anxiety and agitation in dementia. J Psychiatry Neurosci. 2003; 28:6.

54. Landi F, Onder G, Cesari M, Barillaro C, Russo A, Bernabei R. Psychotropic Medications and Risk for Falls Among Community-Dwelling Frail Older People: An Observational Study. The Journals of Gerontology Series A: Biological Sciences and Medical Sciences. 2005; 60:622-626.

55. Wang PS. Hazardous Benzodiazepine Regimens in the Elderly: Effects of Half-Life, Dosage, and Duration on Risk of Hip Fracture. American Journal of Psychiatry. 2001; 158:892-898. [PubMed: 11384896]

56. Sunderland T, Weingartner H, Cohen RM, Tariot PN, Newhouse PA, Thompson KE, Lawlor BA, Mueller EA. Low-dose oral lorazepam administration in Alzheimer subjects and age-matched controls. Journal of Clinical Psychopharmacology. 1990; 10:59.

57. Gage SBD, Moride Y, Ducruet T, Kurth T, Verdoux H, Tournier M, Pariente A, Begaud B. Benzodiazepine use and risk of Alzheimer's disease: case-control study. Bmj. 2014; doi: 10.1136/ bmj.g5205

58. Bellou V, Belbasis L, Tzoulaki I, Middleton LT, Ioannidis JP, Evangelou E. Systematic evaluation of the associations between environmental risk factors and dementia: An umbrella review of systematic reviews and meta-analyses. Alzheimer's \& Dementia. 2016; doi: 10.1016/j.jalz. 2016.07.152

59. National Initiative Examines Antipsychotic Drug Use in the Elderly. Blue Cross Blue Shied of Illinois. 2014:1-2.

60. Dorsey ER, Rabbani A, Gallagher SA, Conti RM, Alexander GC. Impact of FDA Black Box Advisory on Antipsychotic Medication Use. Arch Intern Med. 2010; 170:96-103. DOI: 10.1001/ archinternmed.2009.456 [PubMed: 20065205]

61. Maher AR, Theodore G. Summary of the Comparative Effectiveness Review on Off-Label Use of Atypical Antipsychotics. JMCP Journal of Managed Care Pharmacy 2012. 2012; 18:1-20. DOI: 10.18553/jmcp.2012.18.s5-b.1

62. Maglione, M., Ruelaz Maher, A., Hu, J., Wang, Z., Shanman, R., Shekelle, PG., Roth, B., Hilton, L., Suttorp, MJ., Ewing, BA., Motala, A., Perry, T. Off-Label Use of Atypical Antipsychotics: An Update. Rockville, MD: Agency for Healthcare Research and Quality; Sep. 2011 Comparative Effectiveness Review No. 43. (Prepared by Southern California Evidence-based Practice Center, Contract No. HHSA290-2007-10062-1.)Available at: www.effectivehealthcare.ahrq.gov/reports/ final.cfm

63. Kreys T-JM, Phan SV. A Literature Review of Quetiapine for Generalized Anxiety Disorder. Pharmacotherapy: The Journal of Human Pharmacology and Drug Therapy. 2015; 35:175-188. DOI: $10.1002 /$ phar.1529

64. Muscatello MR, Spina E, Bandelow B, Baldwin DS. Clinically relevant drug interactions in anxiety disorders. Human Psychopharmacology: Clinical and Experimental. 2012; 27:239-253. DOI: 10.1002/hup.2217 [PubMed: 22311403]

65. Schouws SN, Stek ML, Comijs HC, Beekman AT. Risk factors for cognitive impairment in elderly bipolar patients. J Affect Disord. 2010; 125:330-335. [PubMed: 20079932]

66. Diniz BS, Nunes PV, Machado-Vieira R, Forlenza OV. Current pharmacological approaches and perspectives in the treatment of geriatric mood disorders. Curr Opin Psychiatry. 2011; 24(6):473477. DOI: 10.1097/YCO.0b013e32834bb9bd. [PubMed: 21918446]

67. Chuang D-M, Manji HK. Search of the Holy Grail for the Treatment of Neurodegenerative Disorders: Has a Simple Cation Been Overlooked? Biol Psychiatry. 2007; 62:4-6. DOI: 10.1016/ j.biopsych.2007.04.008 [PubMed: 17572175] 
68. Mula M, Pini S, Cassano GB. The Role of Anticonvulsant Drugs in Anxiety Disorders. J Clin Psychopharmacol. 2007; 27:263-272. DOI: 10.1097/jcp.0b013e318059361a [PubMed: 17502773]

69. Masdrakis VG, Papadimitriou GN, Oulis P. Lamotrigine Administration in Panic Disorder With Agoraphobia. Clin Neuropharmacol. 2010; 33:126-128. DOI: 10.1097/wnf.0b013e3181d4c1f6 [PubMed: 20502131]

70. Zavodnick AD, Ali R. Lamotrigine in the Treatment of Unipolar Depression with and Without Comorbidities: A Literature Review. Psychiatr Q 2012. 2012; 83:371-383. DOI: 10.1007/ s11126-012-9208-4

71. Huffman JC, Stern TA. Neuropsychiatric consequences of cardiovascular medications. Dialogues Clin Neurosci. 2007; 9(1):29-45. Huffman and Stern. [PubMed: 17506224]

72. Craske MG, Stein MB. Anxiety. The Lancet. 2016; :1-12. DOI: 10.1016/S0140-6736(16)30381-6

73. Ahmed AI, Mierlo PV, Jansen P. Sleep disorders, nightmares, depression and anxiety in an elderly patient treated with low-dose metoprolol. General Hospital Psychiatry. 2010; 32:646.e5-646.e7.

74. Dharmarajan TS, Dharmarajan L. Tolerability of Antihypertensive Medications in Older Adults. Drugs Aging Drugs \& Aging. 2015; 32:773-796. DOI: 10.1007/s40266-015-0296-3 [PubMed: 26442857]

75. Kubesova HM, Weber P, Meluzinova H, Bielakova K, Matejovsky J. Benefits and pitfalls of cardiovascular medication in seniors. Wiener klinische Wochenschrift. 2013; 125:425-436. DOI: 10.1007/s00508-013-0395-2 [PubMed: 23846454] 


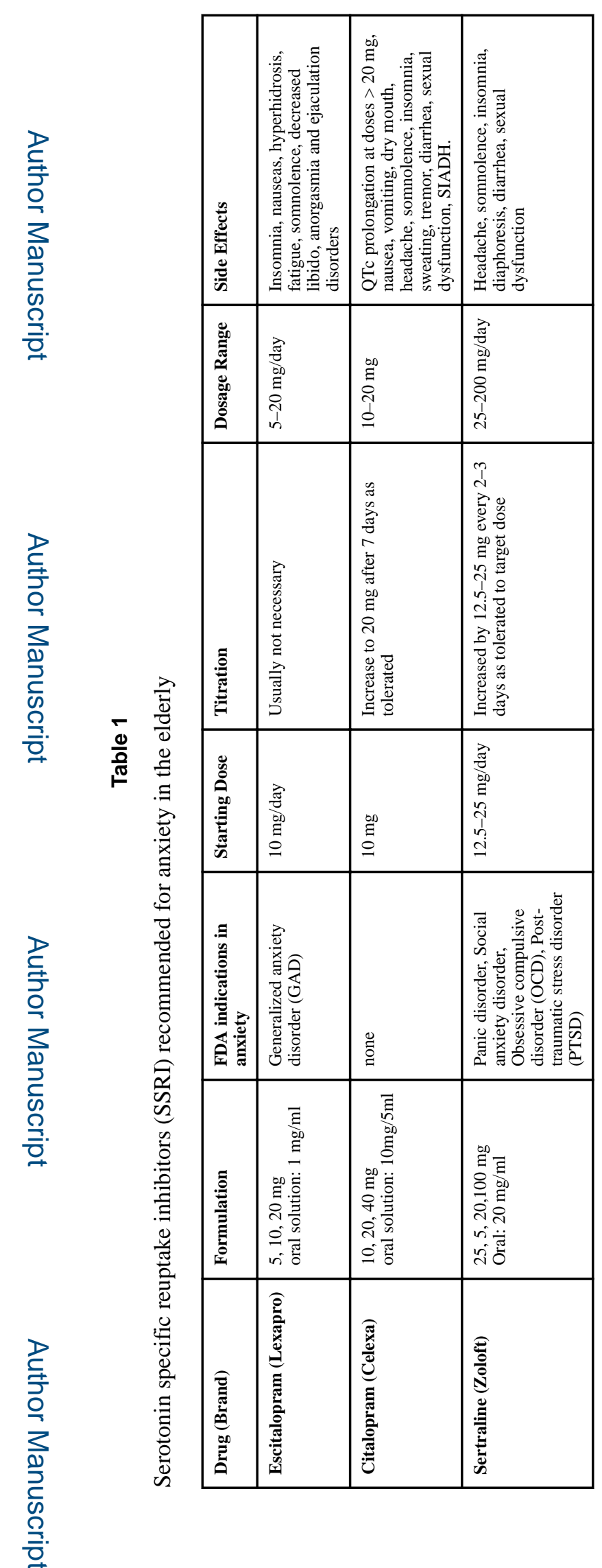

Curr Treat Options Psychiatry. Author manuscript; available in PMC 2018 March 01. 


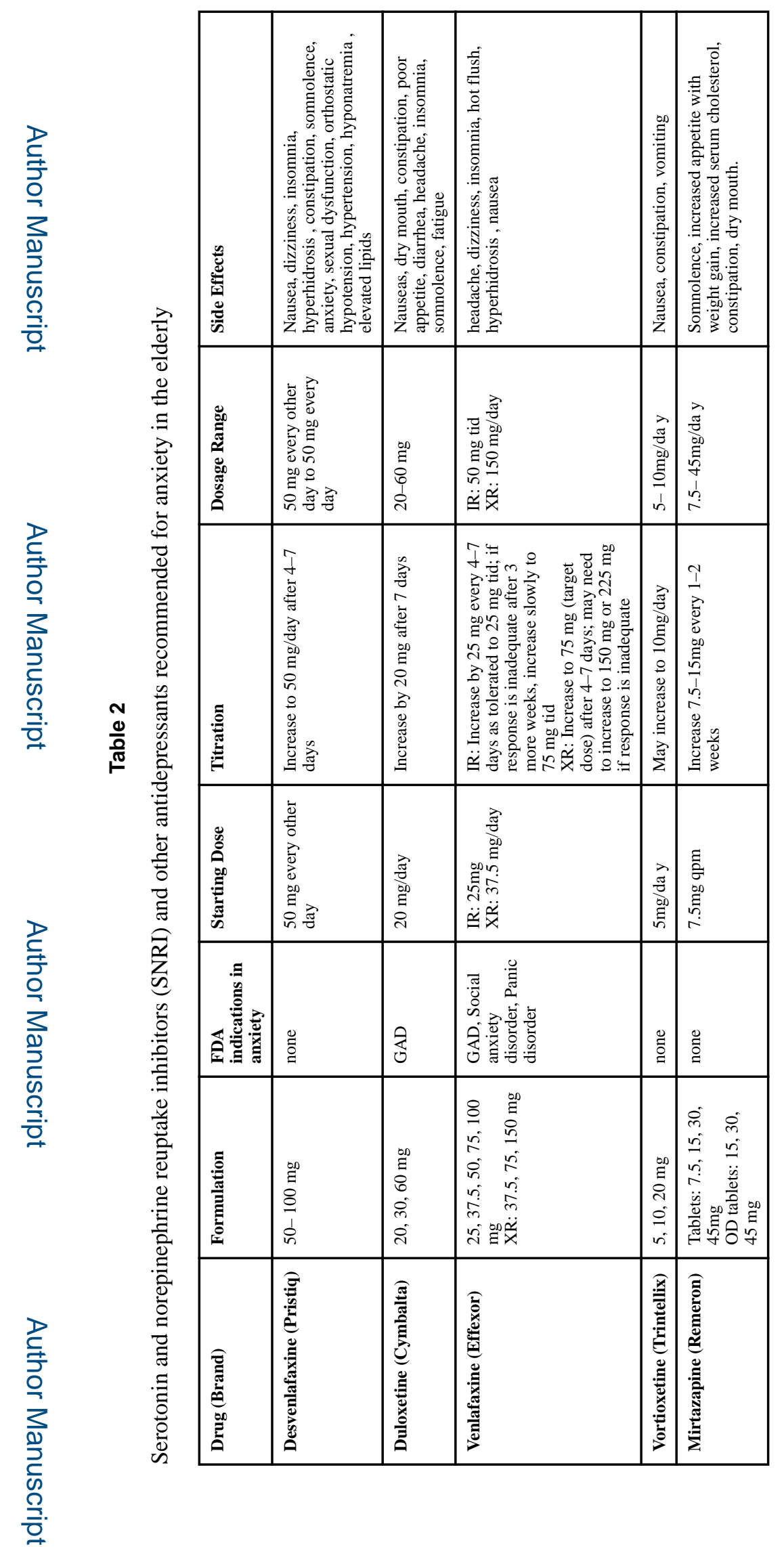

Curr Treat Options Psychiatry. Author manuscript; available in PMC 2018 March 01. 